\title{
AN ATTEMPT AT AN ALGEBRAIC THEORY OF CRYSTAL STRUCTURE. PART 4.
}

\author{
DAVID A ABOAV
}

29 Clements Road, Chorleywood, Hertfordshire, WD3 5JS, UK.

(Accepted July 18, 2000)

\begin{abstract}
Since, for reasons to be examined in a later instalment of this work, the postulates of Euclid do not seem suited for the purpose, an attempt is made to classify regularities in the observed diffraction of X-rays by matter in the crystalline state on a 'Pythagorean', or purely numerical basis
\end{abstract}

Keywords: crystal structure, Yarmolyuk and Kripyakevich's rule.

"I am quite satisfied if we have the machinery for making predictions, even if we are unable to understand it clearly" (Einstein, 1953).

\section{INTRODUCTION}

It has been shown that in some cases the number of polyhedra that go to make up the postulated unit cell of a crystal, and the number of the cell's vertices, are proportional to the solutions of a simple Diophantine equation (Aboav, 1997; 1998a). These solutions do not describe the partition of the cell into its differently shaped polyhedra (Aboav, 1998b), though as we shall see in a moment a further numerical assumption makes such a description possible.

Relations depending on arithmetical operations, like the adding or multiplying of integers, will here be considered separately from those that depend on geometrical ones, such as the measurement of length and angle.

\section{NUMERICAL}

Pythagoras's discovery that the interval of 7 octaves is roughly equal to that of 12 major fifths, i.e. that $2^{7} \sim(3 / 2)^{12}$, or

$$
2^{\mathrm{a}} \sim 3^{\mathrm{b}}
$$

where $\mathrm{a}=19, \mathrm{~b}=12$, may be regarded as a borderline case $(x=y=1)$ of a more general approximation

$$
2^{\mathrm{a}} \mathrm{x} \sim 3^{\mathrm{b}} \mathrm{y}
$$

where $\mathrm{x}$ and $\mathrm{y}$ in this instance are integers, one of which is prime, and the other is either prime, or the product of 5 (or 7) and a prime number.

A pair of composite numbers, $m$ and $n$, are now defined thus:

and

$$
\mathrm{m}=2^{\mathrm{a}} \mathrm{x} / 2^{7}
$$

$$
\mathrm{n}=3^{\mathrm{b}} \mathrm{y} / 3^{6}
$$

Since these numbers are co-prime, $\mathrm{m}$ is not a multiple of $\mathrm{n}$. Their ratio $\mathrm{m} / \mathrm{n}$, here denoted by $\mathrm{A}$, is equal to $\left(2^{\mathrm{a}} \mathrm{x} / 3^{\mathrm{b}} \mathrm{y}\right)\left(3^{6} / 2^{7}\right)$. Hence, since $2^{\mathrm{a}} \mathrm{x} \sim 3^{\mathrm{b}} \mathrm{y}, \mathrm{A}$ is approximately equal to $3^{6} / 2^{7}$, that is,

$$
\text { A } \sim 57
$$

The fraction $1-3^{6} \mathrm{~m} / 2^{7} \mathrm{n}$, or $1-3^{\mathrm{b}} \mathrm{y} / 2^{\mathrm{a}} \mathrm{x}$, which is a measure of how closely $2^{\mathrm{a}} \mathrm{x}$ approximates $3^{\mathrm{b}} \mathrm{y}$, is here denoted by the Greek letter $\kappa$ and called the comma:

$$
\kappa=1-3^{6} \mathrm{n} / 2^{7} \mathrm{~m}
$$

[Note: In the above-quoted, celebrated instance of antiquity, where $m$ and $n$ are effectively put equal to $2^{12}$ and $3^{6}$ respectively, $|\kappa|=1-3^{12} / 2^{19}$, or roughly $1 / 73$. Known to musicians as the comma of Pythagoras, this value of $\kappa$ represents the small but perceptible interval between such notes as $\mathrm{D}^{\mathrm{b}}$ and $\mathrm{C}^{\#}$ played on a violin.]

50 solutions to the approximate relation (2), here denoted by $[\mathrm{a} b]\{\mathrm{x} y\}$, are listed in col. 2 of Table 1 , which shows the relevant values of the co-primes $\mathrm{m}$ and $\mathrm{n}$ (col. 3) and of the comma (col. 4). Solution No. 39 , [6 6] 6 5.5.5 11\}, in which $\mathrm{x}$ is neither prime, nor the product of 5 (or 7) and a prime as required, is exceptionally listed in the table to allow every value of [ $\left.f \begin{array}{ll}f & 1\end{array}\right]$ from $f=1$ through $f=10$ (see Eq. 10 below) to appear in it. 
Table 1. Partition of numbers $m n$ proportional to solutions of 'Pythagorean' approximation $2^{a} x \sim 3^{b} y$.

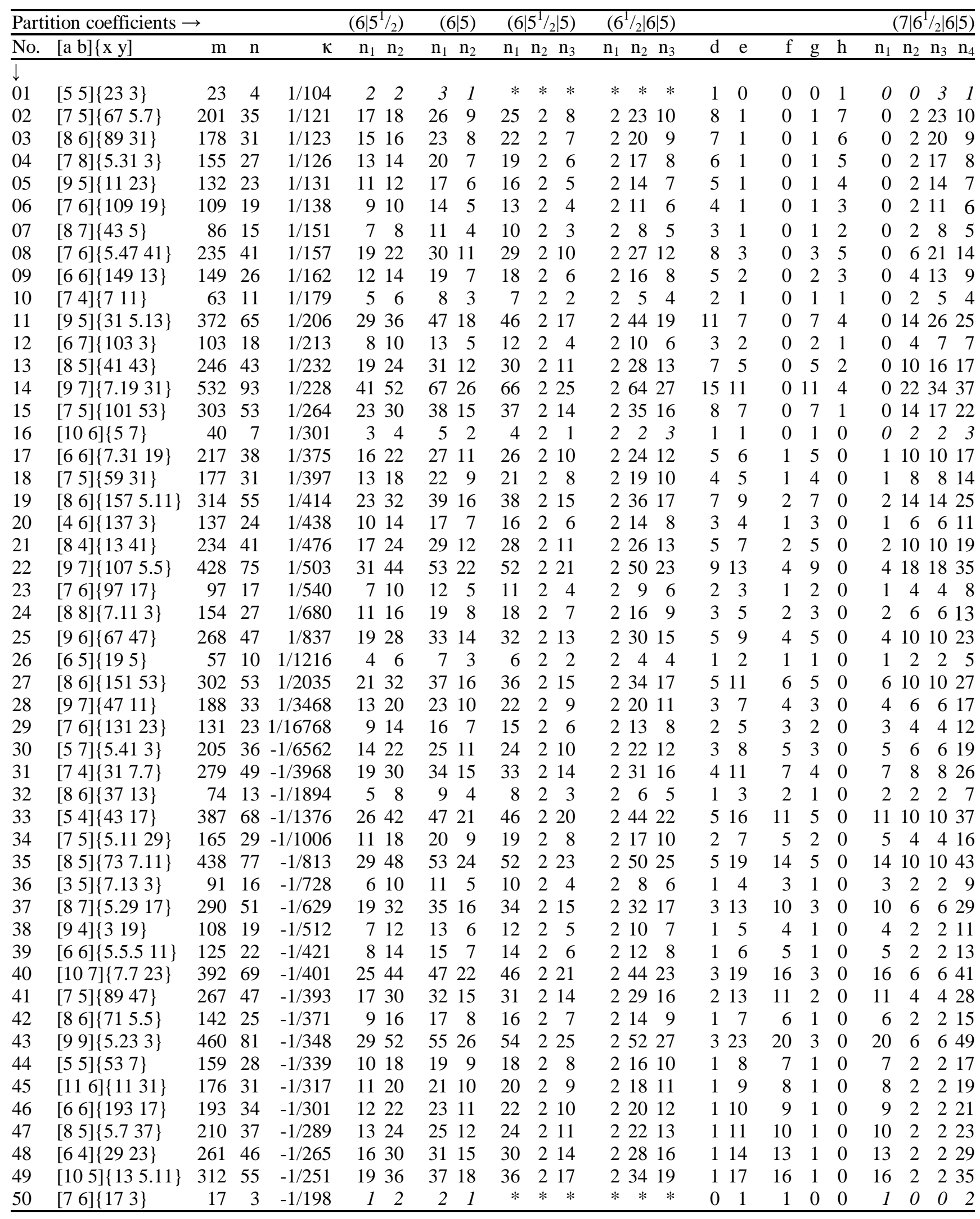

Since by definition the comma cannot equal zero, relation (2) is necessarily approximate only. Exact numerical relations can, however, be found to depend on it by partitioning $\mathrm{m}$ and $\mathrm{n}$ into a finite number, $\mathrm{s}$, 
of positive integers $m_{s}$ and $n_{s}$

$$
\mathrm{m}=\Sigma_{\mathrm{s}} \mathrm{m}_{\mathrm{s}}
$$

and

$$
\mathrm{n}=\Sigma_{\mathrm{s}} \mathrm{n}_{\mathrm{s}}
$$

such that $2 m_{s}$ is a multiple of $n_{s}$ for any value of $s$, that is,

$$
\mathrm{m}_{\mathrm{s}}=\mathrm{A}_{\mathrm{s}} \mathrm{n}_{\mathrm{s}}
$$

where $A_{s}=p$ or $(p+1 / 2), p$ being a positive integer. The partitions depend on the chosen values of $s$ and $\mathrm{A}_{\mathrm{s}}$; but the corresponding values of $\mathrm{n}_{\mathrm{s}}$ are in general indeterminate.

Our attention is here confined to partitions for which $\mathrm{s}=4$, with the aim of determining whether, from among the solutions of Table 1, there exist partitions of that kind for which no value of $n_{s}$ is greater than 3; and, if so, to express the partition of the remaining solutions in the table in terms of them, the underlying object being to base the sought-after partitions on the simplest possible assumptions. To that end the requisite partition coefficients are determined as follows.

$n$ is first expressed as the sum of a pair of integers, $n_{1}$ and $n_{2}$ (col. 5), the chosen values of $A_{s}$ needed to express $\mathrm{m}_{\mathrm{s}}$ being those nearest to $\mathrm{A}$ (Eq. 5), namely $A_{1}=6$, and $A_{2}=5^{1} / 2:\left[\left(6 \mid 5^{1} / 2\right)\right]$; while in col. 6 the next nearest pair of values, $A_{1}=6$, and $A_{2}=5$ : $[(6 \mid 5)]$ is used for the same purpose. The immediate aim is to identify solutions of relation (2) for which no value of $n_{s}$ exceeds 3 . As the data show, there are in this case only two such solutions, namely [5 5]\{23 $3\}$ and $\left[\begin{array}{l}7 \\ 6\end{array}\right]\{173\}$, listed in the table at Nos. 01 and 50 , respectively, with their values of $n_{s}$ shown in italics.

Again with the aim of identifying solutions for which no value of $n_{s}$ exceeds $3, n$ is next expressed as the sum of three integers $\mathrm{n}_{1}, \mathrm{n}_{2}, \mathrm{n}_{3}$ (cols. 7 and 8), the values of $A_{s}$ for col. 7 being the closest to those already chosen, namely $A_{1}=6, A_{2}=5 \frac{1}{2}$, and $A_{3}=5$ : $\left[\left(6\left|5^{1} / 2\right| 5\right)\right]$; while for col.8 the values $A_{1}=6 \frac{1}{2}$, $\mathrm{A}_{2}=6$, and $\mathrm{A}_{3}=5:\left[\left(6^{1} / 2|6| 5\right)\right]$ are chosen. With the partition of $n$ into three numbers in this way the values of $n_{s}$ are in general indeterminate. In the table therefore, where lack of space does not allow more than one of the possible partitions to be shown, $\mathrm{n}_{2}$ in col. 7, and $n_{1}$ in col. 8, are given the same, arbitrarily chosen value 2 . It will be seen that for the partition $\left(6\left|5^{1} / 2\right| 5\right)$ (col. 7) there are no solutions, and that for the partition $\left(6^{1} / 2|6| 5\right)$ (col. 8) there is only one solution --- $\left[\begin{array}{ll}10 & 6\end{array}\right]\left\{\begin{array}{l}5 \\ 7\end{array}\right\}$, listed at No.16 --- for which no value of $n_{s}$ is greater than 3 .
Finally, by introducing the further, proximate coefficient, $A_{1}=7$, into the partition $\left(6^{1 / 2}|6| 5\right)$ of col. 8, which as we have seen already possesses one of the required solutions, we obtain the partition $\left(7\left|6^{1} / 2\right| 6 \mid 5\right)$, in which $n$ is expressed as the sum of four numbers $\mathrm{n}_{1}, \mathrm{n}_{2}, \mathrm{n}_{3}$, and $\mathrm{n}_{4}$. This partition has two further solutions for which no value of $n_{s}$ is greater than 3. The components $\left(\mathrm{n}_{1}, \mathrm{n}_{2}, \mathrm{n}_{3}, \mathrm{n}_{4}\right)$ of the three solutions, namely ( $\left(\begin{array}{llll}0 & 0 & 3 & 1\end{array}\right),\left(\begin{array}{llll}0 & 2 & 2 & 3\end{array}\right)$ and $\left(\begin{array}{llll}1 & 0 & 0 & 2\end{array}\right)$, are listed in italics (Nos. 1, 16, 50) in the last column of Table 1.

These solutions enable the components of $\mathrm{n}$ for the remainder of the column to be expressed as sums of their products with positive integers $\mathrm{f}, \mathrm{g}, \mathrm{h}$, which are functions of $\mathrm{m}$ and $\mathrm{n}$ only, thus:

$\left(\mathrm{n}_{1}+\mathrm{n}_{2}+\mathrm{n}_{3}+\mathrm{n}_{4}\right) \equiv \mathrm{f}\left(\begin{array}{lllll}1 & 0 & 0 & 2\end{array}\right)+\mathrm{g}\left(\begin{array}{lllll}0 & 2 & 2 & 3\end{array}\right)+\mathrm{h}\left(\begin{array}{llll}0 & 0 & 3 & 1\end{array}\right)$

so that the components of $\mathrm{n}$ on the left-hand side of this identity may be equated to the sum of the corresponding products on the right-hand side as follows:

$$
\begin{gathered}
\mathrm{n}_{1}=\mathrm{f} \\
\mathrm{n}_{2}=2 \mathrm{~g} \\
\mathrm{n}_{3}=2 \mathrm{~g}+3 \mathrm{~h} \\
\mathrm{n}_{4}=2 \mathrm{f}+3 \mathrm{~g}+\mathrm{h} .
\end{gathered}
$$

Hence

$$
\begin{gathered}
\mathrm{m}_{1}=7 \mathrm{f} \\
\mathrm{m}_{2}=13 \mathrm{~g} \\
\mathrm{~m}_{3}=12 \mathrm{~g}+18 \mathrm{~h} \\
\mathrm{~m}_{4}=10 \mathrm{f}+15 \mathrm{~g}+5 \mathrm{~h} ;
\end{gathered}
$$

so that

and

$$
\begin{aligned}
\mathrm{n} & =3 \mathrm{f}+7 \mathrm{~g}+4 \mathrm{~h} \\
& =3 \mathrm{u}+4 \mathrm{v},
\end{aligned}
$$

$$
\begin{aligned}
\mathrm{m} & =17 \mathrm{f}+40 \mathrm{~g}+23 \mathrm{~h} \\
& =17 \mathrm{u}+23 \mathrm{v},
\end{aligned}
$$

where $\mathrm{u}=(\mathrm{f}+\mathrm{g})$ and $\mathrm{v}=(\mathrm{g}+\mathrm{h})$. Hence $\mathrm{g} \leq \mathrm{u}$ and $\mathrm{g} \leq \mathrm{v}$. Moreover

$$
m / n=(17 u+23 v) /(3 u+4 v)
$$

i.e.

$$
u(3 m-17 n)=v(23 n-4 m)
$$

or

$$
\mathrm{ud}=\mathrm{ve}
$$

where

and

$$
d=(3 m-17 n),
$$

$$
e=(23 n-4 m)
$$

so that

$$
\begin{gathered}
d+2 e=29 n-5 m \\
=29(3 f+7 g+4 h)-5(17 f+4 g+23 h)
\end{gathered}
$$




$$
=2 \mathrm{f}+3 \mathrm{~g}+\mathrm{h},
$$

from which it follows that

$$
n_{4}=29 n-5 m \text {. }
$$

The choice of coefficients $\left(7\left|6^{1} / 2\right| 6 \mid 5\right)$ thus makes one of the four numbers $n_{s}$, namely $n_{4}$, independent of the partition, the other three numbers, $\mathrm{n}_{1}, \mathrm{n}_{2}, \mathrm{n}_{3}$, being in general indeterminate; though, as Eqs. (11) show, they are subject to the restrictions $n_{1}<n_{4}$, and $n_{2} \leq n_{3}$.

The following illustration, with Nos. 14, 19, and 27 taken as examples (Table 2), shows how the numbers d, e of Eq. (14), which are listed for each of the solutions of Table 1 (col. 9) facilitate the evaluation of $\mathrm{f}, \mathrm{g}, \mathrm{h}$ (col. 10).

Table 2. Some solutions for nos. 14, 19, 27 of Table 1.

\begin{tabular}{lccc}
\hline & no. 14 & no. 19 & no. 27 \\
\hline $\mathrm{d}$ & 15 & 7 & 5 \\
$\mathrm{e}$ & 11 & 9 & 11 \\
$\mathrm{Eq}(14)$ & $15 \mathrm{u}=11 \mathrm{v}$ & $7 \mathrm{u}=9 \mathrm{v}$ & $5 \mathrm{u}=11 \mathrm{v}$ \\
$\mathrm{Sol}^{\mathrm{n}}$ & $\mathrm{u}=11, \mathrm{v}=15$ & $\mathrm{u}=9, \mathrm{v}=7$ & $\mathrm{u}=11, \mathrm{v}=5$ \\
$\mathrm{fg} \mathrm{h}$ & 0114 & 270 & 650 \\
\hline
\end{tabular}

Table 3. Complete solutions for nos. 14, 19, 27 of Table 1.

\begin{tabular}{rrrrrrrrr}
\hline \multicolumn{3}{c}{ no. 14} & \multicolumn{3}{c}{ no. 19 } & \multicolumn{3}{c}{ no. 27} \\
$\mathrm{f}$ & $\mathrm{g}$ & $\mathrm{h}$ & $\mathrm{f}$ & $\mathrm{g}$ & $\mathrm{h}$ & $\mathrm{f}$ & $\mathrm{g}$ & $\mathrm{h}$ \\
\hline 0 & 11 & 4 & 2 & 7 & 0 & 6 & 5 & 0 \\
1 & 10 & 5 & 3 & 6 & 1 & 7 & 4 & 1 \\
2 & 9 & 6 & 4 & 5 & 2 & 8 & 3 & 2 \\
3 & 8 & 7 & 5 & 4 & 3 & 9 & 2 & 3 \\
4 & 7 & 8 & 6 & 3 & 4 & 10 & 1 & 4 \\
5 & 6 & 9 & 7 & 2 & 5 & 11 & 0 & 5 \\
6 & 5 & 10 & 8 & 1 & 6 & & & \\
7 & 4 & 11 & 9 & 0 & 7 & & & \\
8 & 3 & 12 & & & & & & \\
9 & 2 & 13 & & & & & & \\
10 & 1 & 14 & & & & & & \\
11 & 0 & 15 & & & & & & \\
\hline
\end{tabular}

Whereas a single trio of numbers $\mathrm{f}, \mathrm{g}, \mathrm{h}$ as shown in the bottom line of Table 2 represents for these three examples a possible solution of the indeterminate equation (14), to obtain the complete solutions the trios with all possible values of $\mathrm{g}$, in this case those for which $0 \leq \mathrm{g} \leq 1 ; \quad 0 \leq \mathrm{g} \leq 7 ;$ and $0 \leq \mathrm{g} \leq 5$, respectively (Table 3 ), have to be taken into account. These solutions are set out in full in Table 3, beginning in each case with the trio for which $g$ has its largest value, i.e. for which $g=11,7$, or 5 , respectively, and $\mathrm{f}$ or $\mathrm{h}=0$. Since for lack of space not all values of $\mathrm{f}$, $\mathrm{g}, \mathrm{h}$ like those shown in Table 3 can be included in Table 1, only those for which $\mathrm{f}$ and/or $\mathrm{h}=0$ are listed. From these numbers and Eq. (10) a required partition of $n$ (col. 11) can be obtained for each entry in the table, thus realizing the first aim of this investigation.

There remains to be seen, however, whether such a purely numerical system can contribute to the setting up of an axiomatic framework on which to base an adequate description of Nature.

\section{PHYSICAL}

The aspect of Nature to be considered here is the behaviour of light (or, more generally, of radiation) in the presence of matter in the crystalline state, the example chosen being the scattering of X-rays by some tetrahedrally close-packed alloys of the transition metals. Shoemaker and Shoemaker (1986) listed experimental data for 20 such alloys, some metrical properties of whose crystal structure have already been considered (Aboav, 1998b). Our attention is now briefly directed to the topology of the structure.

In Table 4, cols 2 and 3 are the same as cols 10 and 11 of Table 1 . In col. 4 are listed the alloys investigated by Shoemaker and Shoemaker, while $\mathrm{p}$, $\mathrm{q}, \mathrm{r}, \mathrm{x}$, the numbers of 16-, 15-, 14-, and 12-hedra (called P, Q, R, X, respectively) per unit cell of the alloys are given in col. 6 .

For each of these unit cells Yarmolyuk and Kripyakevich (1974) found an empirical formula for $\mathrm{P}_{\mathrm{p}} \mathrm{Q}_{\mathrm{q}} \mathrm{R}_{\mathrm{r}} \mathrm{X}_{\mathrm{x}}$ expressible as

$$
\mathrm{P}_{\mathrm{p}} \mathrm{Q}_{\mathrm{q}} \mathrm{R}_{\mathrm{r}} \mathrm{X}_{\mathrm{X}} \rightarrow\left(\mathrm{PX}_{2}\right)_{\mathrm{i}}\left(\mathrm{Q}_{2} \mathrm{R}_{2} \mathrm{X}_{3}\right)_{\mathrm{j}}\left(\mathrm{R}_{3} \mathrm{X}\right)_{\mathrm{k}}
$$

where $\mathrm{i}, \mathrm{j}, \mathrm{k}$, whose values for the alloys of Shoemaker and Shoemaker are listed in col. 5 of Table 4, are integers. This apparent restriction on the relative values of $\mathrm{p} \mathrm{q} \mathrm{rx}$ is here referred to as the rule of Yarmolyuk and Kripyakevich. As the following fact suggests, the rule being a numerical one may not require a geometrical explanation.

From the above table it will be seen that to each value of [i j k] there corresponds an identical value of [ $\mathrm{g} \mathrm{h}$ ], and to each value of [p q r x] an identical value of $\left[\begin{array}{llll}n_{1} & n_{2} & n_{3} & n_{4}\end{array}\right]$. When these identical numbers are placed in alignment, there appear gaps in the entries of cols. 4-6, which once again suggest that the experimental data may be incomplete (Aboav, 1998b). (Not all the values of [i j k] are equal to those of [ $\mathrm{g} \mathrm{h}$ ] shown in Table 1, those of Nos. 14, 19, and 27 equalling instead the values shown in italics in Table 3, which for lack of space could not, as we have already seen, be included in Table 1.). 
Table 4. Relation of numerical solutions of Table 1 to the crystal structure of some tetrahedrally close-packed alloys (Shoemaker and Shoemaker, 1986).

\begin{tabular}{|c|c|c|c|c|c|c|c|c|c|c|c|c|c|c|c|}
\hline No. & $\mathrm{f}$ & $\mathrm{g}$ & $\mathrm{h}$ & $\mathrm{n}_{1}$ & $\mathrm{n}_{2}$ & $\mathrm{n}_{3}$ & $\mathrm{n}_{4}$ & Alloy & $\mathrm{i}$ & $\mathrm{j}$ & $\mathrm{k}$ & $\mathrm{p}$ & $q$ & $\mathrm{r}$ & $\mathrm{X}$ \\
\hline$\overline{01}$ & 0 & 0 & 1 & 0 & 0 & 3 & 1 & $\mathrm{CrAl}$ & 0 & 0 & 1 & 0 & 0 & 3 & \\
\hline 02 & 0 & 1 & 7 & 0 & 2 & 23 & 10 & & & & & & & & \\
\hline 03 & 0 & 1 & 6 & 0 & 2 & 20 & 9 & & & & & & & & \\
\hline 04 & 0 & 1 & 5 & 0 & 2 & 17 & 8 & & & & & & & & \\
\hline 05 & 0 & 1 & 4 & 0 & 2 & 14 & 7 & & & & & & & & \\
\hline 06 & 0 & 1 & 3 & 0 & 2 & 11 & 6 & & & & & & & & \\
\hline 07 & 0 & 1 & 2 & 0 & 2 & 8 & 5 & $\mathrm{CrFe}$ & 0 & 1 & 2 & 0 & 2 & 8 & 5 \\
\hline 08 & 0 & 3 & 5 & 0 & 6 & 21 & 14 & & & & & & & & \\
\hline 09 & 0 & 2 & 3 & 0 & 4 & 13 & 9 & & & & & & & & \\
\hline 10 & 0 & 1 & 1 & 0 & 2 & 5 & 4 & & & & & & & & \\
\hline 11 & 0 & 7 & 4 & 0 & 14 & 26 & 25 & & & & & & & & \\
\hline 12 & 0 & 2 & 1 & 0 & 4 & 7 & 7 & & & & & & & & \\
\hline 13 & 0 & 5 & 2 & 0 & 10 & 16 & 17 & & & & & & & & \\
\hline 14 & 0 & 11 & 4 & 0 & 22 & 34 & 37 & $\mathrm{MnSi}$ & 6 & 5 & 10 & 6 & 10 & 40 & 37 \\
\hline 15 & 0 & 7 & 1 & 0 & 14 & 17 & 22 & & & & & & & & \\
\hline 16 & 0 & 1 & 0 & 0 & 2 & 2 & 3 & $\mathrm{ZrAl}$ & 0 & 1 & 0 & 0 & 2 & 2 & 3 \\
\hline 17 & 1 & 5 & 0 & 1 & 10 & 10 & 17 & & & & & & & & \\
\hline 18 & 1 & 4 & 0 & 1 & 8 & 8 & 14 & & & & & & & & \\
\hline 19 & 2 & 7 & 0 & 2 & 14 & 14 & 25 & $\mathrm{MnFeSi}$ & 7 & 2 & 5 & 7 & 4 & 19 & 25 \\
\hline 20 & 1 & 3 & 0 & 1 & 6 & 6 & 11 & & & & & & & & \\
\hline 21 & 2 & 5 & 0 & 2 & 10 & 10 & 19 & & & & & & & & \\
\hline 22 & 4 & 9 & 0 & 4 & 18 & 18 & 35 & & & & & & & & \\
\hline 23 & 1 & 2 & 0 & 1 & 4 & 4 & 8 & & & & & & & & \\
\hline 24 & 2 & 3 & 0 & 2 & 6 & 6 & 13 & & & & & & & & \\
\hline 25 & 4 & 5 & 0 & 4 & 10 & 10 & 23 & & & & & & & & \\
\hline 26 & 1 & 1 & 0 & 1 & 2 & 2 & 5 & & & & & & & & \\
\hline 27 & 6 & 5 & 0 & 6 & 10 & 10 & 27 & $\mathrm{MrCrCo}$ & 8 & 3 & 2 & 8 & 6 & 12 & 27 \\
\hline 28 & 4 & 3 & 0 & 4 & 6 & 6 & 17 & & & & & & & & \\
\hline 29 & 3 & 2 & 0 & 3 & 4 & 4 & 12 & & & & & & & & \\
\hline 30 & 5 & 3 & 0 & 5 & 6 & 6 & 19 & & & & & & & & \\
\hline 31 & 7 & 4 & 0 & 7 & 8 & 8 & 26 & & & & & & & & \\
\hline 32 & 2 & 1 & 0 & 2 & 2 & 2 & 7 & МoCo & 2 & 1 & 0 & 2 & 2 & 2 & 7 \\
\hline 33 & 11 & 5 & 0 & 11 & 10 & 10 & 37 & & & & & & & & \\
\hline 34 & 5 & 2 & 0 & 5 & 4 & 4 & 16 & & & & & & & & \\
\hline 35 & 14 & 5 & 0 & 14 & 10 & 10 & 43 & & & & & & & & \\
\hline 36 & 3 & 1 & 0 & 3 & 2 & 2 & 9 & & & & & & & & \\
\hline 37 & 10 & 3 & 0 & 10 & 6 & 6 & 29 & & & & & & & & \\
\hline 38 & 4 & 1 & 0 & 4 & 2 & 2 & 11 & VNiSi & 4 & 1 & 0 & 4 & 2 & 2 & 11 \\
\hline 39 & 5 & 1 & 0 & 5 & 2 & 2 & 13 & & & & & & & & \\
\hline 40 & 16 & 3 & 0 & 16 & 6 & 6 & 41 & & & & & & & & \\
\hline 41 & 11 & 2 & 0 & 11 & 4 & 4 & 28 & & & & & & & & \\
\hline 42 & 6 & 1 & 0 & 6 & 2 & 2 & 15 & VCoSi & 6 & 1 & 0 & 6 & 2 & 2 & 15 \\
\hline 43 & 20 & 3 & 0 & 20 & 6 & 6 & 49 & MgZnAl & 20 & 3 & 0 & 20 & 6 & 6 & 49 \\
\hline 44 & 7 & 1 & 0 & 7 & 2 & 2 & 17 & & & & & & & & \\
\hline 45 & 8 & 1 & 0 & 8 & 2 & 2 & 19 & & & & & & & & \\
\hline 46 & 9 & 1 & 0 & 9 & 2 & 2 & 21 & & & & & & & & \\
\hline 47 & 10 & 1 & 0 & 10 & 2 & 2 & 23 & $\mathrm{MnCoSi}$ & 10 & 1 & 0 & 10 & 2 & 2 & 23 \\
\hline 48 & 13 & 1 & 0 & 13 & 2 & 2 & 29 & & & & & & & & \\
\hline 49 & 16 & 1 & 0 & 16 & 2 & 2 & 35 & $\mathrm{MgZn}$ & 16 & 1 & 0 & 16 & 2 & 2 & 35 \\
\hline 50 & 1 & 0 & 0 & 1 & 0 & 0 & 2 & $\mathrm{MgZn}$ & 1 & 0 & 0 & 1 & 0 & 0 & 2 \\
\hline
\end{tabular}

It is remarkable that, despite their different origin, relations (2) and (16) should furnish identical groups of numbers, either of which can be used to describe the same topological property of a crystal's structure. This identity is not to be expected, since relation (2) has nothing to do with the notions of geometry that 
play a seemingly essential part in our customary interpretation of the X-ray photograph of a crystal. A doubt therefore arises as to whether this phenomenon requires such notions for its description.

Such doubts are not new: indeed, a century-and-ahalf has elapsed since Riemann (1854), recognizing that the rules of everyday geometry do not necessarily apply in cases where, as for example in Haüy's (1784) 'molecular' picture of a crystal, the scale is so reduced that the notions of the solid body and the ray of light are no longer valid, expressed the opinion:

“...es ist also sehr wohl denkbar, dass die Massverhältnisse des Raumes im Unendlichkleinen den Voraussetzungen der Geometrie nicht gemäss sind, und dies würde man in der That annehmen müssen, sobald sich dadurch die Erscheinungen auf einfacherer Weise erklären liessen.” (Riemann, 1854).

("....it is thus quite conceivable that relations of size on an infinitesimally small scale are not in accord with the postulates of geometry, and this one would indeed have to assume, as soon as it allowed the phenomena to be more simply accounted for.")

This doubt, which haunts us still, is not easy to allay; for, in seeking to be rid of it, not only are we faced with the task of finding suitable assumptions to take the place of those laid down in the Elements, but history has left little or no trace of the discoveries and decisions known to have been made by Pythagoras and his successors in the 2 centuries before the publication of that great work, discoveries and decisions which must have played no small part in determining the path Euclid was eventually to follow and which would help us immeasurably in our present task, could we but know what they were. All we can do, alas, is to guess what they may have been and try to reconstruct the route by which Euclid arrived at his assumptions, an undertaking we venture to hazard in the next instalment of this work.

(to be continued)

\section{REFERENCES}

Aboav DA (1997). An attempt at an algebraic theory of crystal structure. Acta Stereol.

Aboav DA (1997). An attempt at an algebraic theory of crystal structure. Acta Stereol, 16:41-53; 1998a.

Aboav DA (1997). An attempt at an algebraic theory of crystal structure. Acta Stereol, 17:113-22; 1998b

Aboav DA (1997) An attempt at an algebraic theory of crystal structure. Acta Stereol, 17:273-82.

Einstein A (1953). Letter to M Born dated December 3.

Haüy R-J (1784). Essai d'une théorie sur la structure des crystaux. Paris.

Riemann B (1854). Ueber die Hypothesen welche der Geometrie zu Grunde liegen. Göttingen.

Shoemaker DP and Shoemaker CB (1986). The relative number of atomic coordination types in tetrahedrally close packed metal structures. Acta Cryst B46:3-11.

Yarmolyuk YP and Kripyakevich PI (1974). (Kristallografiya, 1974, 19:539-45) Sov Phys Crystallogr 19:334-7. 